\title{
Bulls, Bears and Excess Volatility: can currency intervention help?*
}

\author{
Luisa Corrado, $^{\dagger} \quad$ Marcus Miller, ${ }^{\ddagger} \quad$ Lei Zhang ${ }^{\S}$
}

January 2007

\begin{abstract}
Asset mis-pricing may reflect investor psychology, with excess volatility arising from switches of sentiment. For a floating exchange rate where fundamentals follow a random walk, we show that excess volatility can be generated by the repeated entry and exit of currency 'bulls' and 'bears' with switches driven by 'draw-down' trading rules. We argue that non-sterilised intervention - in support of 'monitoring band' - can reduce excess volatility by coordinating beliefs in line with policy. Strategic complementarity in the foreign exchange market suggests that sterilised intervention may also play a coordinating role.
\end{abstract}

JEL: D52, F31, G12.

Key-Words: Monitoring Rules, Monitoring Band, Bear and Bull Traders, Excess Volatility, Central Bank Intervention.

${ }^{*}$ The paper has benefited from comments received at the CIMF conference on Exchange Rate Intervention: Theory and Policy at Cambridge (September 7th-8th 2006), and in particular those of our discussant Paul Weller. We thank Sayantan Ghosal and anonymous referees for comments and helpful criticism. Luisa Corrado gratefully acknowledges funding by the Marie-Curie Intra-European Fellowship 514913 and Marcus Miller and Lei Zhang financial support by ESRC Grants RES-051-27-0125 and RES-156-25-0032 respectively.

${ }^{\dagger}$ Faculty of Economics, University of Cambridge and University of Rome, Tor Vergata.

${ }^{\ddagger}$ Department of Economics, University of Warwick and CEPR.

${ }^{\S}$ Department of Economics, University of Warwick. 


\section{Introduction}

When the euro was created in 1999 some economists predicted that it would rise strongly from its launch value of $\$ 1.18$ as it challenged the dollar's position as the world's key reserve currency. ${ }^{1}$ The euro bulls were disappointed, however, as the new currency steadily lost value - perhaps because Asian countries lost faith in the IMF and turned to the dollar as a substitute. When the euro fell to 83 cents in September 2000, coordinated Central Bank intervention was implemented to stop the slide. A famously incautious remark by the then head of $\mathrm{ECB}^{2}$ led to further weakness (with the euro falling to its historic minimum a month later), but the euro stabilized around 90 cents (Figure 1). From early 2002, the currency experienced a reversal that was to take it well above the launch price, reaching a peak of $\$ 1.36$ near the end of 2004. Currently, with the euro standing close to $\$ 1.30$, there is talk of further dollar devaluation to help reduce the US deficit.

The substantial - and surprising - gyrations in the euro/dollar rate have led to calls for the publication of sustainable or 'equilibrium exchange rates'. John Williamson for example has suggested that this would be an appropriate initiative for the IMF which - as part of its new medium term strategy - aims to involve itself more closely with the affairs of G8 countries. It has been officially argued, however, that any such steps would be unattractive - even embarrassing - for the ECB and the Fed, neither of which have the exchange rate as a policy target. Both players reserve the right to intervene at values which they may judge to be inappropriate: save for such ad hoc intervention, things should be left to market forces.

How will market forces operate if there is asymmetric information in firms trading foreign currency, and heterogeneity in the type of trader to whom portfolio management is delegated? Can intervention help in these circumstances? These are the questions addressed in this paper.

In financial markets where asset management is delegated to agents with private information, traders will typically be subject to monitoring rules. When trades involve signalling the quality of the trader as well as the asset, Dasgupta and Prat $(2005,2006)$ have shown that even traders who are

\footnotetext{
${ }^{1}$ Bergsten (1997) and Portes and Rey (1998) for example.

${ }^{2}$ When asked whether a slump in currencies caused by a war in the Middle East might lead central banks to intervene in the markets, Mr Duisenberg said, "I wouldn't think so".
} 


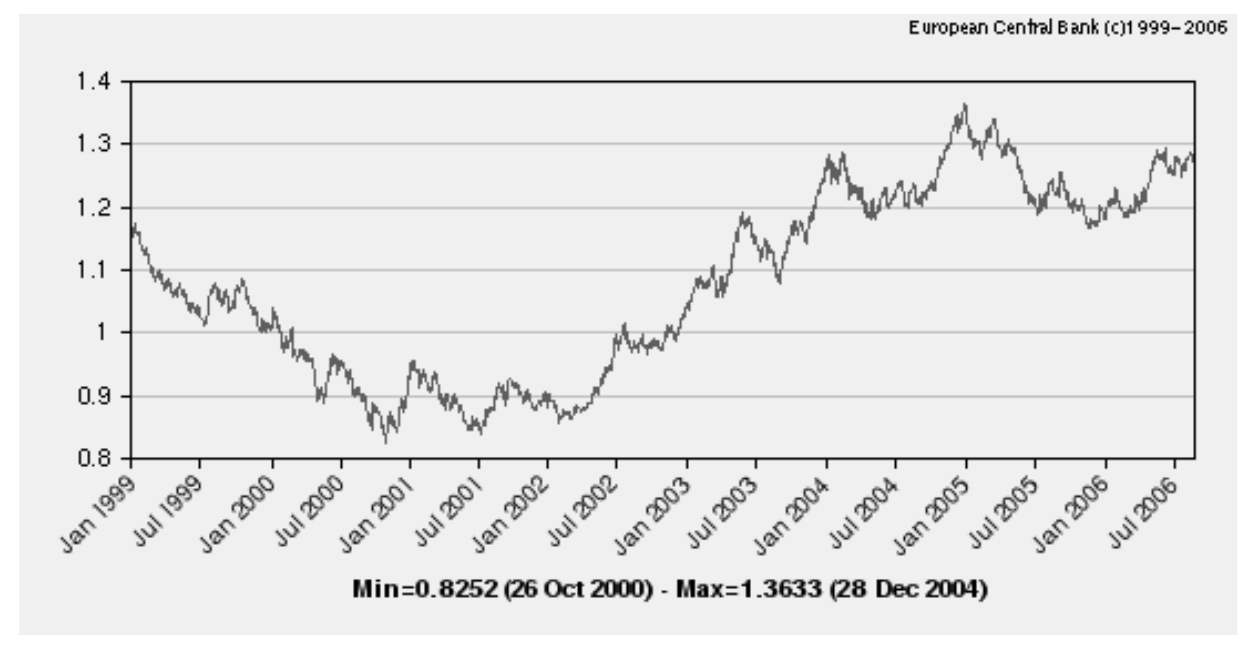

Figure 1: The value of the Euro since its launch in Jan 1999. Source: ECB.

being optimally monitored will fail to push prices to equilibrium; though they begin trading sincerely, they will eventually 'follow the herd'. With ad hoc monitoring rules, the risk of market inefficiency is much greater, as Grossman and Zhou (1993) show for 'draw-down rules' that involve firing traders who lose more than a given percent of previous peak value for the assets under management.

Asset mis-pricing may reflect investor psychology, with excess volatility arising from switches of sentiment, as Barberis et al (1998) have argued with respect to the equity market. Like them, we postulate two types of trader in the foreign exchange market - 'bulls' and 'bears' - each with a distinct psychological bias in forming expectations. For a floating exchange rate where fundamentals follow a random walk, we show how excess volatility can be generated by the repeated entry and exit of currency 'bulls' and 'bears' where the switches are driven by a 'draw-down' rule as in Grossman and Zhou (1993). ${ }^{3}$

In this simple model we show how official intervention can reduce excess volatility. ${ }^{4}$ The intervention we discuss involves changing fundamentals by non-sterilised intervention if and when the rate moves outside what

\footnotetext{
${ }^{3}$ An alternative approach where trading rules are selected using a fitness criterion is explored by De Grauwe and Grimaldi (2006) and Kubelec (2004).

${ }^{4}$ See Krugman and Miller (1992) for a similar argument in connection with target zones.
} 
Williamson has labelled 'monitoring bands'. We argue that the trend that this introduces into fundamentals will help stabilise the rate directly via its effects on selecting between bulls and bears.

The paper proceeds as follows. In Section 2, we show how the entry and exit of bulls and bears changes the behaviour of an exchange rate driven by random walk fundamentals. In Section 3 we see how the 'churning' of traders can generate excess volatility. Can this excess volatility - induced by trading strategies and noisy fundamentals - be reduced by implementing a monitoring band? In Section 4 we show that non-sterilised intervention, by its effects in selecting between bulls and bears, can reduce exchange rate volatility. Before concluding, there is a brief discussion of the coordination role of sterilised currency intervention in the context of strategic complementarity.

\section{A one-time switch between 'bears' and 'bulls'}

In Barberis et al (1998), a representative risk neutral investor is assumed to switch between two 'sentiments' in respect to stock earnings - trend extrapolation and mean-reversion. While earnings actually follow a random walk, the investor switches between these sentiments based on runs of data from markets. Here it is the psychological forces of conservatism and representativeness operating on the ultimate wealth owner that play a key role in updating beliefs.

Our focus is on funds under management, however, so the operative mechanism is the set of rules governing currency traders in a situation of asymmetric information between principal and agent ${ }^{5}$. We assume there are two types of traders to whom currency portfolio management may be delegated - 'bulls' who are optimistic about the trend-value of domestic currency and 'bears' who are pessimistic.

In the absence of official intervention, fundamentals are assumed to follow a random walk:

$$
d x=\sigma d W
$$

\footnotetext{
${ }^{5}$ The approach we have adopted applies to equities as well, as wealth owners commonly leave funds under management for investment by equity traders: indeed the draw-down rules we use are discussed by Grossman and Zhou with respect to equity investment.
} 
where $W$ is a standard Wiener process and $\sigma$ the instantaneous standard deviation. But 'bulls' and 'bears' are subject to psychological biases in forming their expectations: their anticipated future exchange rates deviate from rational expectations. ${ }^{6}$

Bulls consistently over-estimate and bears always under-predict the trend in exchange rates. Specifically, we assume domestic currency bulls will add a fixed appreciation premium to the mathematical expectation of the exchange rate change, despite fundamentals following random walk, so:

$$
E^{O} d u / d t=E d u / d t+\mu
$$

where $u$ represents the $(\log )$ price of domestic currency in terms of foreign currency, ${ }^{7} E^{O}$ indicates 'optimistic' expectations of euro bulls, $E$ the rational expectations and $\mu$ the appreciation premium. Similarly, the change in the exchange rate expected by bears will lie below its mathematical expectation change by a term that represents their bearishness for domestic currency, which for convenience we also assume to be $\mu:{ }^{8}$

$$
E^{P} d u / d t=E d u / d t-\mu,
$$

where $E^{P}$ represents pessimistic expectations of the bears.

At any given time, only one type of trader will populate the market. So our bullishness and bearishness resemble the two sentiments postulated in Barberis et al (1998). But while they postulate changes of sentiment on the part of ultimate wealth holders, we assume assets under management are switched between bulls and bears in response to public signals: when losses from some previous market peak hit the limit set by a 'draw-down' rule, for example, as in Grossman and Zhou (1993). If draw-down rules are the same across the market then the market as a whole will switch at once, so traders at any point of time will be homogenous - which is what we assume. Note that in both our model and that of Barberis et al (1998), it is the change of beliefs not the trading of assets which affects prices.

\footnotetext{
${ }^{6}$ Much of the psychological biases associated with how people form expectations were summarised in Barberis and Thaler (2003).

${ }^{7}$ In this paper, we take euro as the domestic currency and dollar the foreign currency.

${ }^{8}$ The 'observational equivalence' between trend expectation and risk aversion is noted further below.
} 


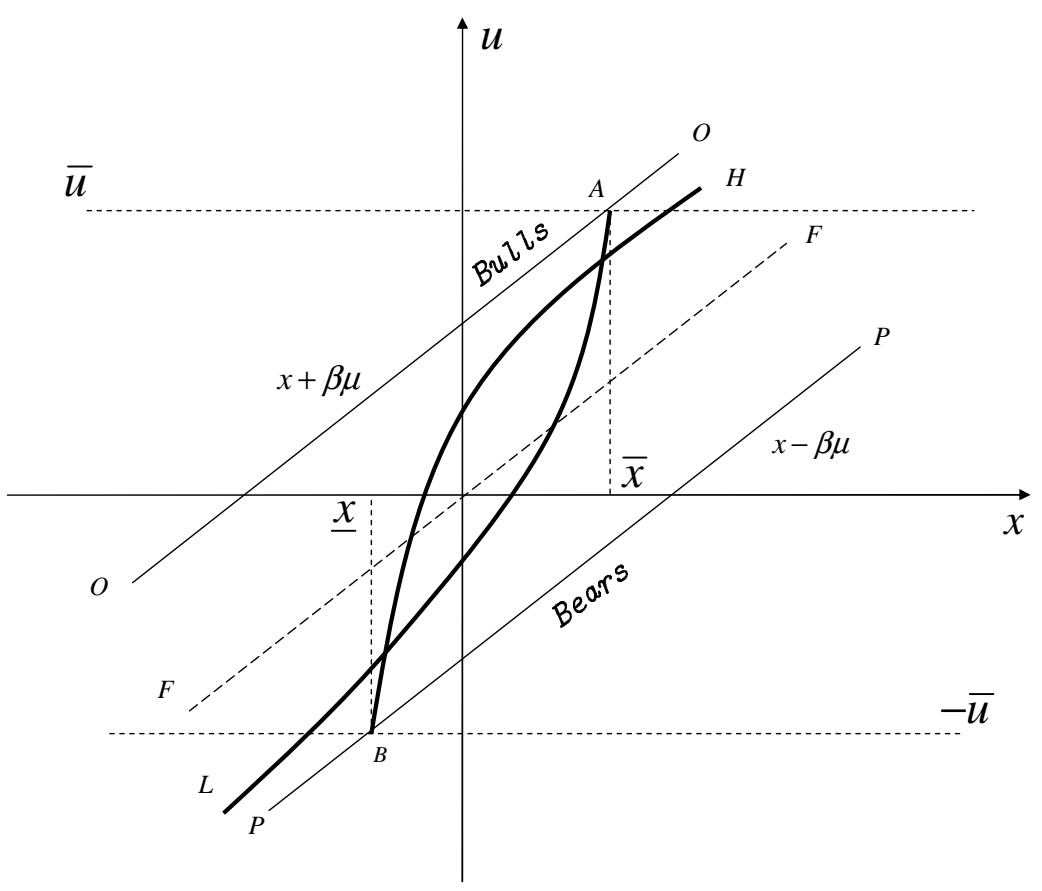

Figure 2: Misalignment and volatility with a one-time switch.

If bulls were permanently in the market, the arbitrage condition for the exchange rates is simply:

$$
\frac{1}{2} \sigma^{2} u_{O}^{\prime \prime}(x)+\mu=\frac{1}{\beta}\left(u_{O}(x)-x\right),
$$

where subscript $O$ represents bulls. With no-bubble-condition, (2) has the solution:

$$
u_{O}(x)=x+\beta \mu .
$$

So with bulls permanently in the market, exchange rates would have a misalignment of $\beta \mu$. (Likewise, the exchange rates with bears permanently in the market are given by $u_{P}(x)=x-\beta \mu$, where subscript $P$ indicates bears.)

Figure 2 illustrates how the presence of bears and bulls affects exchange rates. Using the horizontal axis to represent fundamentals and vertical the exchange rate, the $45^{\circ}$ line $F F$ represents the fundamental value for exchange rates when $x$ follows a random walk (with $\mu=0$ ). The lines $O O$ (denoting optimism) and $P P$ (denoting pessimism) indicate respectively the 
outcomes if local currency bulls or bears are permanently in the market. Notice that, without switching, the volatility of exchange rates is not affected in either case.

How will switching between trader types impact on exchange rates and currency volatility? To start with the exchange rate effect, assume that for high values of $u$ only euro-bulls will be in the market: but they will be replaced by euro-bears if and when the value of $u$ falls to $-\bar{u}$. Symmetrically, only euro-bears will be in the market for low $u$, with a switch in market composition at $\bar{u}$. On these assumptions, the solutions for the exchange rates (formally derived in Appendix A) are as shown in Figure 2.

The concave curve $H A$ represents solution for bulls who expect to be driven out of the market at $A$. The exit of bulls at $A$ is locally irreversible, so only value-matching applies. As there are no bears in the market for exchange rates above $\bar{u}$ and the prospect of a switch declines for higher values of fundamentals, the bulls' solution approaches $O O$ asymptotically. (The exchange rate under bears is sketched symmetrically, shown by the convex curve $L B$.) It is clear from the figure that within the bounds of $-\bar{u}$ and $\bar{u}$, exchange rates exhibit hysteresis: if bulls are in the market, they will stay there until $-\bar{u}$ is reached (vice versa for the bears). Note that this switch generates significant persistence in exchange rate misalignment: take the bulls' solution for example, as long as $x$ is sufficiently larger than $\bar{x}$, $u_{O}(x)-x \approx \beta \mu$.

As the instantaneous volatility of the exchange rate is measured by the absolute value of its slope, there will be excess volatility with entry and exit. This is clear from the convex solution for bears which, while asymptotic to $P P$ as $x$ tends to $-\infty$, increases monotonically as $x$ approaches $\bar{x}$ from below. The reason why the anticipated switch adds to volatility is easy to see. Starting at $L$, for example, where the market is dominated by euro-pessimists, consider an increase in the variable $x$, representing fundamentals; the euro will increase in value both for fundamental reasons and also because the market anticipates that the euro-bears are more likely to lose their jobs. As can be seen from Figure 3, volatility for bears is everywhere larger than one and reaches a maximum at $\bar{x}$, the point of switching. Likewise for bulls, volatility reaches its maximum as $x$ approaches $-\bar{x}$ from above. With repeated switches, misalignment is reduced but volatility stays high, as shown in the next section. 


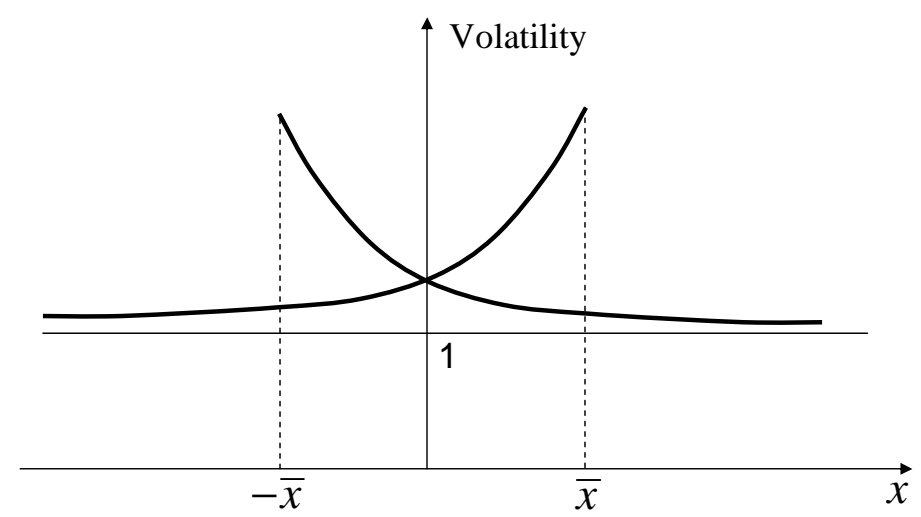

Figure 3: Exchange rate volatility with one-time switch between bull and bears.

\section{$3 \quad$ Repeated switching of traders}

Consider exchange rate behaviour when traders are fired and hired repeatedly under a draw-down rule. Formal results derived in Appendix B are illustrated in Figure 4. Exchange rates must lie between the two lines labelled $u_{L I}$ and $u_{U I}$ each representing a "switching boundary". Consider two solutions lying between fundamental values of $y$ and $z$, which act as triggers for firing and hiring as the vertical distance of $2 \bar{u}$ between the exchange rates $L$ and $H$ corresponds to the draw-down rule of Grossman and Zhou (1993). Thus the concave solution, labelled $u_{O}^{R}$, shows the outcome for the exchange rate when traders are all euro-bulls who fear losing their jobs at $L$ where fundamentals have moved against the euro in favour of the dollar. By symmetry, the solution $u_{P}^{R}$ shows how the exchange rate will behave when trades are being conducted by euro-bears fearing to lose their jobs at $H$.

Together these segments describe a range of hysteresis rather like that observed in the one-time switching case shown in the previous figure. The difference here is that - when fundamentals move sufficiently in the direction predicted by current traders - these line segments will simply slide between the switching boundaries to which they 'smooth-paste' as shown in the figure. ${ }^{9}$ At $H$ for example, with bulls in charge, a positive shock will lead to the concave segments sliding up along the switching boundary. A negative

\footnotetext{
${ }^{9}$ In particular, the convex $u_{P}^{R}$ smooth pastes line $u_{L I}$ at point $L$ and concave $u_{O}^{R}$ smooth pastes line $u_{U I}$ at point $H$. For the rules of "the art of smooth-pasting", see Dixit (1994).
} 


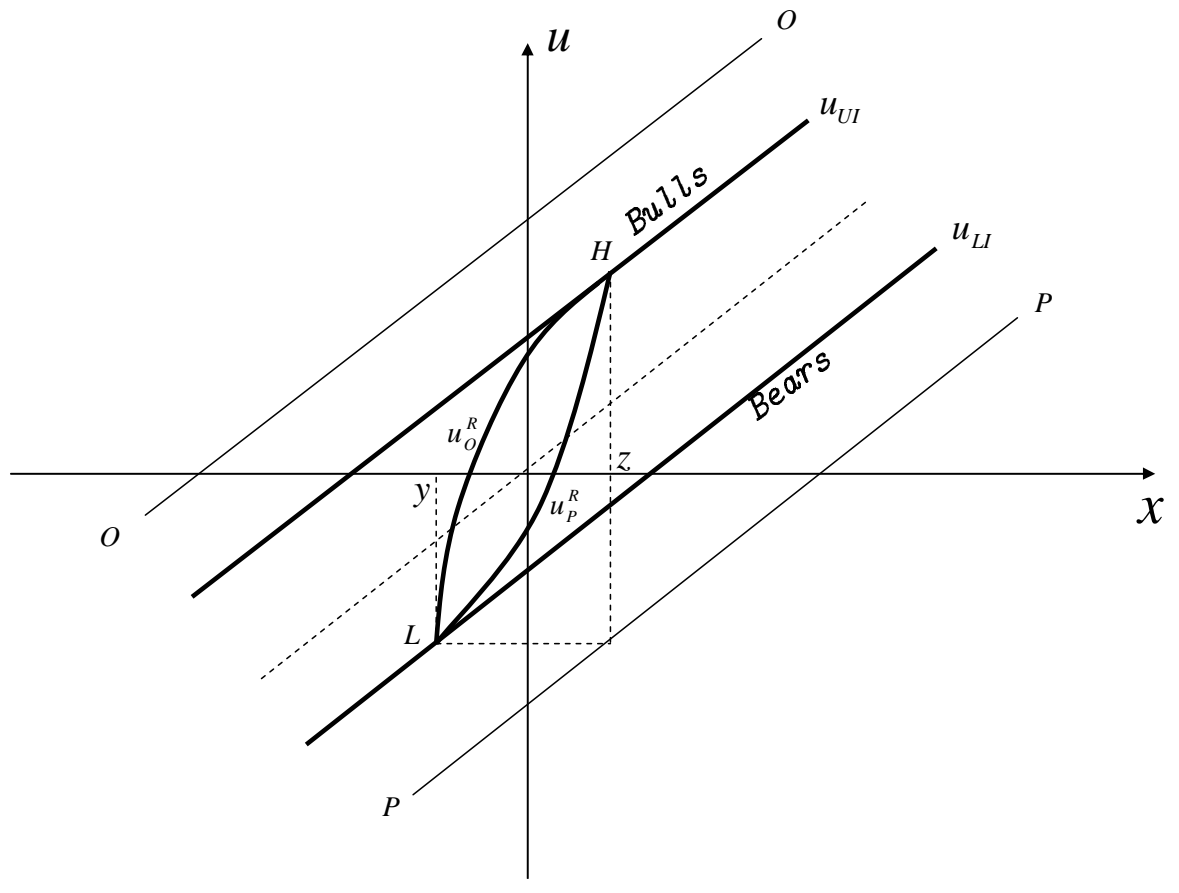

Figure 4: Excess volatility with repeated switching. 
shock involves no sliding, however, as the rate moves down along $u_{O}^{R}$.

The smooth-pasting reflects the fact that traders do not lose their jobs if the rate moves in the direction that they have been forecasting; and the sliding reflects the shifting of the trigger for the draw-down rule as a new currency peak is realized. The switching boundaries $u_{U I}$ and $u_{L I}$ lie inside $P P$ and $O O$ because traders are never sure to keep their jobs. At point $H$ on $u_{U I}$ for instance, euro-bulls are in place, but they are not permanently in place: they expect to lose their jobs if fundamentals move sufficiently against the dollar (for example, to point $L$ ).

Since both $u_{O}^{R}$ and $u_{P}^{R}$ are steeper than $45^{\circ}$, except at the extremities where they smooth-paste, we conclude:

Proposition 1 For repeated switching, there is excess volatility of exchange rates almost everywhere.

The exchange rate effects of repeated switching between bulls and bears as shown in Figure 4 closely resembles that described in Krugman and Miller (1993, Figure A2) where the switching is between risk averse wealth owners and risk neutral stop loss traders subject to draw-down rules. This is not coincidence: it reflects the fact that, in the stochastic framework we are using here, risk aversion manifest itself as a trend. This 'observational equivalence' means that one may be able to apply the results we obtain here to the case where heterogeneity reflects risk preferences and not optimism or pessimism per se.

\section{A monitoring band with non-sterilised interven- tion}

So far our analysis of the foreign exchange market has run closely parallel to Barberis et al (1998) for equities. While fundamentals follow a random walk, agents choose between two contrasting beliefs or 'models' of fundamentals neither of which is strictly rational; and excess volatility arises from random switching between these beliefs based on runs of data from the market.

In this section, we turn to a phenomenon relatively common in foreign exchange markets but not in equity markets, namely official stabilising intervention as a matter of public policy. With non-sterlised intervention, the 
stance of monetary policy can be adjusted to stabilise the exchange rate tightening money to strengthen the currency when it is too weak, easing to lower its external value. In the case of what Williamson (1998) has called 'monitoring bands', stabilising action to push the rate towards a defined equilibrium will be taken when rates lie outside the band, with no action taken close to equilibrium within the band. Unlike a 'target zone', therefore, this soft buffer is perfectly consistent with rates lying outside the monitoring band. But monetary fundamentals will be affected: instead of following a pure random walk, they will incorporate stabilising trends.

How, if at all, might this affect trading rules and the selection of bulls versus bears? Within the band, where fundamentals follow a random walk, there need be no effect; so the draw-down rules discussed previously could well continue in operation. But outside the band intervention will, in principle, move fundamentals closer to one of the two views. If the euro is too strong for example, an easing of monetary policy will mean euro bulls are betting against the trend in fundamentals, while euro bears are going with the flow. In these circumstances, it seems probable that trading rules would be adjusted to be more accommodating to those whose beliefs are consistent with the fundamentals inclusive of intervention; and tougher on those who are not. Instead of trying to model in detail how to endogenise the trading rules, we simply assume that, outside the band, traders whose beliefs are more consistent with fundamentals are selected by those with funds under management. This means that bears are selected when the strength of the euro leads to monetary easing - and bulls when monetary policy is tightened to help the currency when weak; as we see below, stabilising intervention acquires added force if market sentiment moves in line with policy in this fashion.

To study the effects of implementing a monitoring band along the line advocated by Williamson (1998), we adopt the following assumptions:

(i) The monitoring band - within which there is no intervention - lies symmetrically around the origin with half-width $\bar{u}$ : i.e., the size of the monitoring band is the same as that of the draw-down rule. ${ }^{10}$

(ii) Non-sterilised "mean-reverting" intervention occurs outside these limits and is publicly observed. For concreteness we assume that above $\bar{u}$ an intervention in the form of a negative trend of $-\mu d t$ is applied to fundamen-

\footnotetext{
${ }^{10}$ This convenient assumption avoids 'churning' inside the monitoring band.
} 


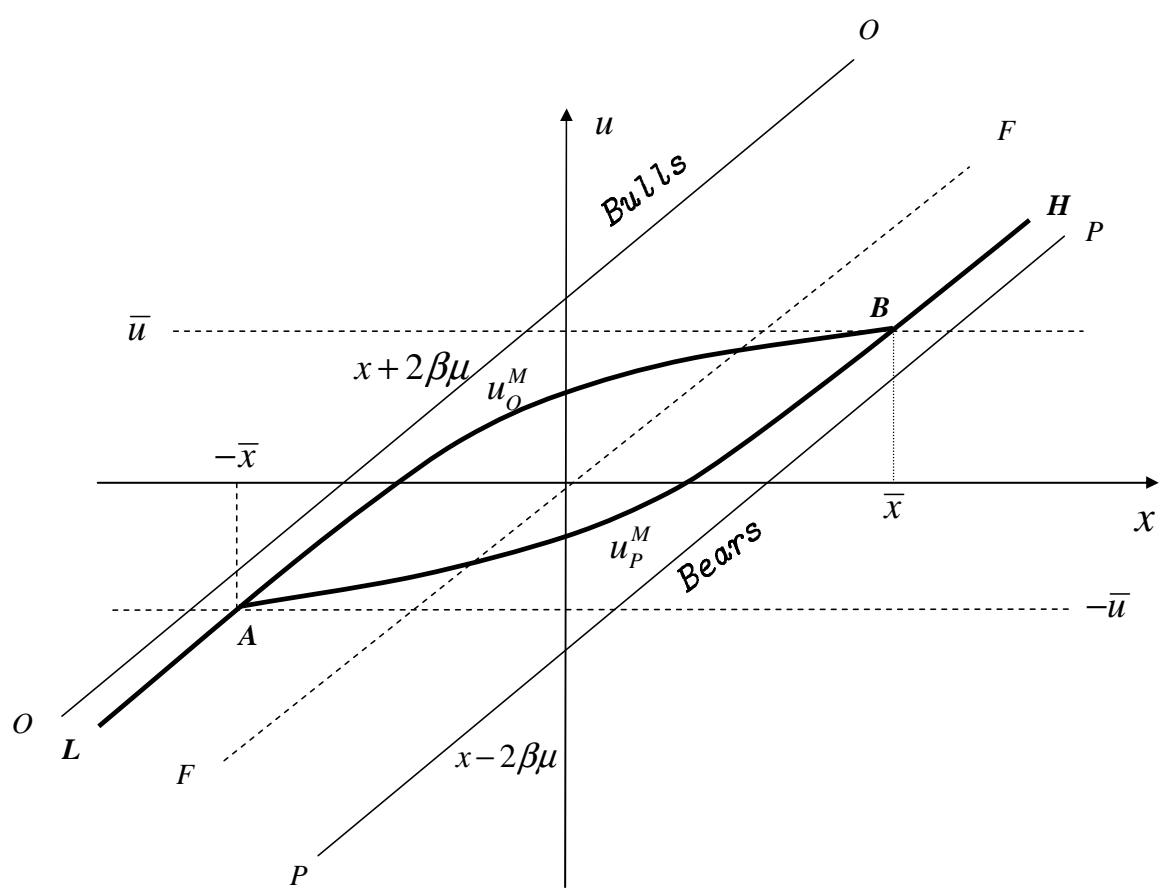

Figure 5: Entry and exit of bulls and bears with a monitoring band.

tals, and conversely a positive trend of $\mu d t$ below $-\bar{u}$. Note, however, policy could take the form of randomized intervention with the same expected value. ${ }^{11}$

(iii) Following the above discussion, intervention is associated with selection of bulls or bears depending the its direction: so at $\bar{u}$ (and above) bears are selected and at $-\bar{u}$ (and below) bulls are selected.

The formal results in Appendix $\mathrm{C}$ are illustrated in Figure 5, where the convex schedule $A B H$ indicates the solution when traders are euro-bears and concave $L A B$ when trades are being carried out by euro-bulls. Note that outside the monitoring band there are no switches and the traders in place have beliefs that coincide with official policy of 'mean-reverting' intervention. As there is no intervention inside the band, the convex segments $H B$ and $B A$

\footnotetext{
${ }^{11}$ Note that the non-sterilised intervention which adds a negative trend $-\mu d t$ to the fundamentals corresponds to monetary expansion: and a positive trend to monetary contraction. For simplicity, the trend intervention is set equal to the expectations bias of traders.
} 


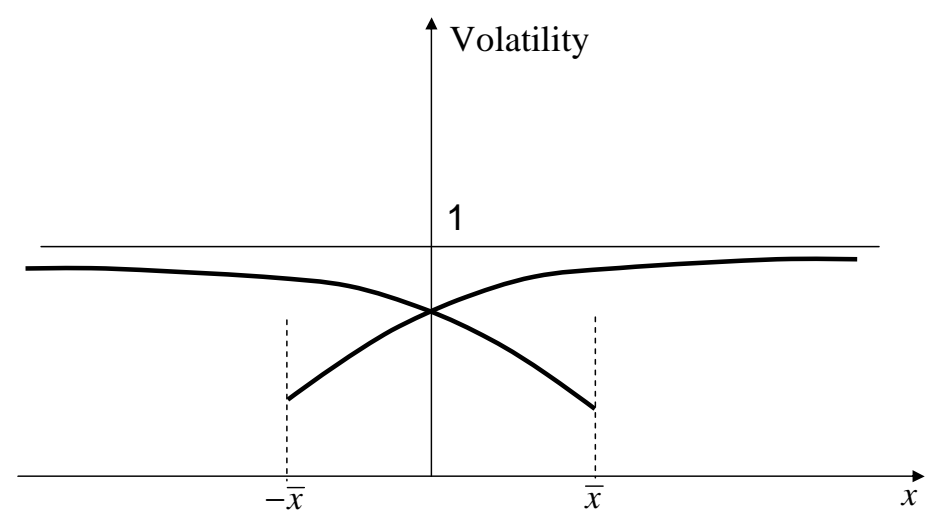

Figure 6: Exchange rate volatility with entry and exit of bull and bears under a monitoring band.

value-match and smooth-paste at $B$, where the stochastic process changes. The linked solution segments $u_{P}^{M}$ and $u_{O}^{M}$ value-match at the top and at the bottom of the band (at the fundamental triggers $\pm \bar{x}$ ). They are therefore a good deal flatter than the sliding segments in the previous section. This may be summarized as follows:

Proposition 2 With a credible monitoring band, the volatility of exchange rates is everywhere less than one.

To see this, note that as $A B H$ is convex and asymptotically approaches $x-2 \beta \mu$ when $x \rightarrow \infty$, the slope of $A B H$ is everywhere less than 1 . This implies that excess volatility for the bear's solution with monitoring band is substantially reduced, indicating the stabilizing power of the monitoring band. The same argument applies to the exchange rate solution for bulls $L A B$.

That short run volatilities lie everywhere below 1 in the presence of nonsterilised intervention is shown in Figure 6. Although intervention only takes place outside the band, volatility is always lower inside the band. This is because of expected switches between bulls and bears.

Our results involve a good deal of hysteresis: we believe this is largely due to the assumption that the draw-down rule matches the size of the band. The effect of varying the size of the draw-down rule remains to be 
explored. $^{12}$

\section{$5 \quad$ A role for sterilised intervention?}

What about sterilised intervention, where the stance of monetary policy is left unchanged? Even when macroeconomic fundamentals are unchanged, sterilised intervention can make a difference if strategic complementarity is a feature of the market (i.e., where it is tempting to buy when you believe others will do the same), as pointed out by Obstfeld (1996) in discussing speculative attacks on a currency peg.

Applying the logic of global games to the foreign exchange market with many small traders with private information on fundamentals - Morris and Shin (1998) found that equilibrium will be unique. The presence of large players can nevertheless affect the behaviour of the market as a whole, as shown by Corsetti et al (2004) and Frankel et al (2003). Taking as an example, provision of liquidity support by the IMF to countries under exchange rate pressure, Corsetti et al (2006) conclude that "Limited contingent liquidity support helps to prevent liquidity runs by raising the number of investors willing to lend to the country for any given fundamentals, i.e., it can have catalytic effects."

Are these appropriate micro-foundations for the "coordination channel" of sterilised intervention discussed in Sarno and Taylor (2001, 2002)? Note that for such coordination benefits to materialize, it must be common knowledge that there will be official intervention at some point. (In a more general setting where homogenous traders possess private information and type of the policy-maker is uncertain, Angeletos et al (2006) show that raising and lowering interest rates may still play a coordinating role - by acting as a signal of policy-maker's type.)

\section{Conclusions}

Traders may have different models or beliefs about the prospects for a currency; and trading rules which generate repeated switches between bulls and

\footnotetext{
${ }^{12}$ In the limiting case analysed Corrado et al (2002) where draw-down rule is arbitrarily small, hysteresis disappears.
} 
bears can cause excess volatility in the foreign exchange market. Official intervention can have self-fulfilling properties if it can appropriately affect traders choice of belief. This has been shown in a setting with heterogenous traders and a publicly-announced policy of non-sterilised intervention. Note, however, that this involves assigning monetary policy to external targets albeit on a state-contingent basis.

In a setting where traders are distinguished not by heterogenous beliefs but by idiosyncratic information, it has been shown that sterilised intervention can play a coordinating role. To get the benefits from coordination in such a global game setting, it appears that a Central Bank must either announce ex-ante its willingness to intervene as a big player, or it must be ready to use interest rates aggressively in order to signal its type. Neither of these seems true of the stance of policy for the euro or the dollar at the time of writing: but things might well change if China chooses to diversify its reserve holdings. 


\section{References}

[1] Angeletos, G.A., C.H. Hellwig and A.P. Pavan (2006): "Signaling in a Global Game: Coordination and Policy Traps," Journal of Political Economy, 114(3), 452-84.

[2] Barberis, N., A. Shleifer And R. Vishny (1998), "A model of investor sentiment", Journal of Financial Economics, 49, 307-43.

[3] Barberis, N. and R. Thaler (2003), "A Survey of Behavioral Finance", in G.M. Constantinides, M. Harris and R. Stulz (eds), Handbook of the Economics of Finance, Elsevier Science.

[4] Bergsten, C. F. (1997), "The Dollar and the Euro" , Foreign Affairs, 76(40), 83-93.

[5] Corrado, L., Miller, M. H. And L. Zhang (2002): "Exchange Rate Monitoring Band: Theory and Policy", CEPR DP 3337.

[6] Corsetti G., A. Dasgupta, S. Morris and H. S. Shin (2004), "Does One Soros Make a Difference? A Theory of Currency Crises with Large and Small Traders," Review of Economic Studies, 71(1), 87-113.

[7] Corsetti, G., B. Guimaraes and N. Roubini (2006): "International lending of last resort and moral hazard: A model of IMF's catalytic finance," Journal of Monetary Economics, 53(3), 441-71.

[8] Dasgupta, A. And A. Prat (2006): 'Financial equilibrium with career concerns'. Theoretical Economics, 1, 67-93.

[9] Dasgupta, A. And A. Prat (2005): "Asset price dynamics when traders care about reputation" Mimeo. LSE.

[10] Dixit, A. (1994): The Art of Smooth-Pasting, Harwood Academic Publishers, Switzerland.

[11] De Grauwe, P. And M. Grimaldi (2006): The Exchange Rate in a Behavioral Finance Framework, Princeton University Press, New Jersey.

[12] Frankel, D. M., S. Morris and A. Pauzner (2003): "Equilibrium selection in global games with strategic complementarities," Journal of Economic Theory, 108(1), 1-44. 
[13] Grossman, S. J. And Z. Zhou (1993): "Optimal Investment Strategies for Controlling Drawdowns", Mathematical Finance, 3 (3), 241-276.

[14] Krugman, P. and M. H. Miller (1993): "Why Have a Target Zone?", Carnegie-Rochester Conference Series on Public Policy, vol. 38, pp. 279-314.

[15] Kubelec, C. (2004): "Intervention When Exchange Rate Misalignments Are Large," in C. F. Bergsten and J. Williamson (eds.) Dollar Adjustment: How Far? Against What? , IIE: Washington DC.

[16] Morris, S. And H. S. Shin (1998): "Unique Equilibrium in a Model of Self-Fulfilling Currency Attacks," American Economic Review, 88(3), 587-97.

[17] Obstfeld, M. 1996: "Models of currency crises with self-fulfilling features," European Economic Review, 40(3-5), 1037-47.

[18] Portes, R., And H. Rey (1998): "The emergence of the euro as an international currency", Economic Policy, 26, 307-343.

[19] Sarno, L. and M. P. Taylor(2001): "Official Intervention in the Foreign Exchange Market: Is It Effective, and, If So, How Does it Work?", Journal of Economic Literature, vol 39, 839-68.

[20] Sarno, L. And M. P. TAYlor (2002): The Economics of Exchange Rates. Cambridge and New York: Cambridge University Press.

[21] Williamson J. (1998): "Crawling Bands or Monitoring Bands: How to Manage Exchange Rates in a World of Capital Mobility", International Finance, 1 (1), 59-79. 


\section{Appendix}

\section{A One-Time Switching}

For the exposition in the text, we assume a relatively large draw-down rule, $\bar{u}>\beta \mu$. With bulls in the market (i.e., $u(x) \geq-\bar{u}$ ), the exchange rate is a solution to (2):

$$
u_{O}(x)=x+\beta \mu+A_{+} \exp (\lambda x)+A_{-} \exp (-\lambda x),
$$

where $A_{ \pm}$are two arbitrary constants to be determined by boundary conditions. When bears are in the market, the arbitrage condition is characterized by

$$
\frac{1}{2} \sigma^{2} u_{P}^{\prime \prime}(x)-\mu=\frac{1}{\beta}\left(u_{P}(x)-x\right), \text { for } u \leq \bar{u}
$$

which permits the following general solution

$$
u_{P}(x)=x-\beta \mu+B_{+} \exp (\lambda x)+B_{-} \exp (-\lambda x) .
$$

To determine completely the solutions for the entry and exit, we specify the following boundary conditions. Note first that, when $u>\bar{u}$, there are only bulls in the market. So for $u \rightarrow \infty$, we must have the asymptotic condition

$$
\lim _{x \rightarrow \infty} u_{O}(x) \rightarrow x+\beta \mu
$$

and likewise,

$$
\lim _{x \rightarrow-\infty} u_{P}(x) \rightarrow x-\beta \mu .
$$

Applying (A.3) and (A.4) to (A.1) and (A.2) respectively yields $A_{+}=B_{-}=$ 0 .

Assume that entries (and exits) are anticipated, and denote the fundamental trigger for the entry of bears (and exit of bulls) by $-\bar{x}$, then no-arbitrage implies the following value matching condition

$$
u_{O}(-\bar{x})=-\bar{u}=-\bar{x}-\beta \mu
$$

By symmetry,

$$
u_{P}(\bar{x})=\bar{u}=\bar{x}+\beta \mu
$$


Solving (A.1) subject to (A.5) yields the solution for bulls

$$
u_{O}(x)=x+\beta \mu-2 \beta \mu \exp [-\lambda(x+\bar{x})], \quad x \geq-\bar{x},
$$

The solution for bears is

$$
u_{P}(x)=x-\beta \mu+2 \beta \mu \exp [\lambda(x-\bar{x})], \quad x \leq \bar{x},
$$

and the entry or exit trigger can be determined by

$$
\bar{x}=\bar{u}-\beta \mu .
$$

\section{B Repeated Switching}

Let $u_{U}$ and $u_{L}$ denote respectively exchange rates when bulls and bears are permanently in place, then

$$
\begin{aligned}
& u_{U}=x+\beta \mu \\
& u_{L}=x-\beta \mu .
\end{aligned}
$$

These solutions correspond to $O O$ and $P P$ in Figure 4. The upper and lower envelopes for repeated switching, denoted by $u_{U I}$ and $u_{L I}$, will lie in the interior of $u_{U}$ and $u_{L}$. Specifically, let them be:

$$
\begin{aligned}
& u_{U I}=x+\beta \mu^{\prime} \\
& u_{L I}=x-\beta \mu^{\prime}
\end{aligned}
$$

where $0<\mu^{\prime}<\mu$ and $\mu^{\prime}$ need to be determined.

Let $u_{O}^{R}$ and $u_{P}^{R}$ be the solutions for bulls and bears subject to switching, then:

$$
\begin{aligned}
& u_{O}^{R}=x+\beta \mu+D_{+} e^{\lambda x}+D_{-} e^{-\lambda x} \\
& u_{P}^{R}=x-\beta \mu+A_{+} e^{\lambda x}+A_{-} e^{-\lambda x}
\end{aligned}
$$

where $D_{ \pm}$and $A_{ \pm}$depend on the switching point $y$ but $\mu^{\prime}$ and $\Delta x=z-y$ are independent from it. Because of symmetry we only need to solve for $u_{O}^{R}$.

Since bulls are expected to leave the market when fundamentals reach point $y$, one condition to be imposed is value matching at $L$ :

$$
u_{O}^{R}(y)=u_{L I}(y)
$$


Bulls solution around point $H$ has features that: following a positive shock to the fundamental at $z$, it slides along the upper envelope $u_{U I}$ resetting the reference for the draw-down rule to the new peak reached; after a negative shock, it simply moves down along $u_{O}^{R}$ to the left. Since there is no change of market composition, $u_{O}^{R}$ value-matches and smooth pastes the upper envelope at $H$ :

$$
u_{O}^{R}(y+\Delta x)=u_{U I}(y+\Delta x)
$$

and

$$
\partial u_{O}^{R}(z) /\left.\partial z\right|_{z=y+\Delta x}=1 .
$$

From (B.2), (B.3) and (B.1):

$$
\cosh (\lambda \Delta x)=\frac{2\left(\mu+\mu^{\prime}\right)}{\mu-\mu^{\prime}} .
$$

Since it takes $2 \bar{u}$ to switching we derive $\mu^{\prime}$ from the following condition:

$$
u_{U I}(y+\Delta x)-u_{L I}(y)=\Delta x+2 \beta \mu^{\prime}=2 \bar{u}
$$

whereas $\Delta x$ is derived by replacing $\mu^{\prime}$ in (B.4) using (B.5): ${ }^{13}$

$$
\cosh (\lambda \Delta x)=\frac{2(2 \beta \mu+2 \bar{u}-\Delta x)}{2 \beta \mu-2 \bar{u}+\Delta x}
$$

where $0<\Delta x<2 \bar{u}+2 \beta \mu$.

For a given $y$ and $\Delta x$ determined by (B.6), one can represent bulls solution in the region $y \leq x \leq y+\Delta x$ by

$$
u_{O}^{R}(x ; y)=x+\beta \mu-\frac{2 \beta \mu-2 \bar{u}+\Delta x}{2} \cosh [\lambda(x-y-\Delta x)] .
$$

It can be easily shown that $u_{O}^{R}$ given in (B.7) is concave. Following the similar procedure, one can derive $u_{P}^{R}$ and show it is convex.

\footnotetext{
${ }^{13}$ Note that the RHS of (B.6) is decreasing in $\Delta x$ and the LHS increasing in $\Delta x$ thus defining a unique solution.
} 


\section{Monitoring Bands and Monitoring Rules}

Because of the symmetry of the monitoring band and the interventions, the fundamental triggers beyond which intervention policy is implemented will be symmetric. Denote these trigger by $-\bar{x}$ and $\bar{x}$. Inside the monitoring band $(-\bar{x} \leq x \leq \bar{x})$ either bulls or bears can be in the market. The solution for bulls inside the monitoring band can be written as

$$
u_{O}^{N}(x)=x+\beta \mu+A_{+}^{N} \exp (\lambda x)+A_{-}^{N} \exp (-\lambda x) .
$$

For $x<-\bar{x}$, official intervention with positive trend to the fundamental is applied. This implies that only bulls are in the market. The arbitrage condition for exchange rates becomes

$$
\frac{1}{2} \sigma^{2} u_{O}^{\prime \prime}(x)+\mu u_{O}^{\prime}(x)+\mu=\frac{1}{\beta}\left[u_{O}(x)-x\right],
$$

which permits a solution of

$$
u_{O}^{I}(x)=x+2 \beta \mu+A_{+}^{I} \exp \left(\xi_{+} x\right)+A_{-}^{I} \exp \left(\xi_{-} x\right),
$$

where $\xi_{ \pm}=\left(\mu \pm \sqrt{\mu^{2}+2 \sigma^{2} / \beta}\right) / \sigma^{2}$, and superscripts $N$ and $I$ represent with and without intervention respectively.

At $\bar{x}$, bulls are fired, only value matching condition applies

$$
u_{O}^{I}(-\bar{x})=\bar{u} .
$$

At $-\bar{x}$, value matching and smooth pasting conditions apply

$$
\begin{aligned}
u_{O}^{N}(-\bar{x}) & =u_{O}^{I}(-\bar{x})=-\bar{u}, \\
d u_{O}^{N}(-\bar{x}) / d x & =d u_{O}^{I}(-\bar{x}) / d x .
\end{aligned}
$$

As in the previous section, similar asymptotic condition applies to $x<-\bar{x}$, i.e.,

$$
\lim _{x \rightarrow-\infty} u_{O}^{N}(x) \rightarrow x+2 \beta \mu .
$$

These boundary conditions imply a fixed point equation for $\bar{x}$ :

$$
\beta \mu=(\bar{u}+2 \beta \mu-\bar{x}) \frac{1+\cosh (2 \lambda \bar{x})+\left(\xi_{+} / \lambda\right) \sinh (2 \lambda \bar{x})}{3+\cosh (2 \lambda \bar{x})},
$$

which has a unique solution $0<\bar{x}<\bar{u}+2 \beta \mu$. 
Given $\bar{x}$ from (C.4), one can then solve for the coefficients in (C.1) and (C.3):

$$
\begin{aligned}
& A_{-}^{I}=0 \\
& A_{+}^{I}=(\bar{x}-\bar{u}-2 \beta \mu) \exp \left(\xi_{+} \bar{x}\right), \\
& A_{-}^{N}=\frac{\beta \mu+\left(1-\xi_{+} / \lambda\right)(\bar{x}-\bar{u}-2 \beta \mu)}{2} \exp (-\lambda \bar{x}), \\
& A_{+}^{N}=\frac{\beta \mu+\left(1+\xi_{+} / \lambda\right)(\bar{x}-\bar{u}-2 \beta \mu)}{2} \exp (\lambda \bar{x}) .
\end{aligned}
$$

So exchange rates under bulls are

$$
u_{O}^{M}(x)=\left\{\begin{array}{l}
x+\beta \mu+(\bar{x}-\bar{u}-2 \beta \mu)\left(\cosh [\lambda(x+\bar{x})]+\left(\xi_{+} / \lambda\right) \sinh [\lambda(x+\bar{x})]\right) \\
\quad+\beta \mu \cosh [\lambda(x+\bar{x})], \text { for }-\bar{x} \leq x \leq \bar{x} \\
x+2 \beta \mu+(\bar{x}-\bar{u}-2 \beta \mu) \exp \left[\xi_{+}(x+\bar{x})\right], \text { for } x<-\bar{x} .
\end{array}\right.
$$

The solution above is indeed concave.

By symmetry, the solution for the bears can be constructed as

$$
u_{P}^{i}(x)=-u_{O}^{i}(-x), \quad i=N, I .
$$

